\title{
Clinical Presentation and Outcome of Ruptured Uterus in A Tertiary Hospital
}

Kazi Farhana Noor ${ }^{1}$

Farida Yasmin ${ }^{2 *}$

Rupasree Biswas ${ }^{3}$

Moumita Tripura Mumu ${ }^{4}$

Uma Dev ${ }^{5}$

${ }^{1}$ Department of Obstetrics and Gynecology Upazila Health Complex, Patiya

Chittagong, Bangladesh.

${ }^{2}$ Department of Obstetrics and Gynecology Chittagong Medical College Chittagong, Bangladesh.

${ }^{3}$ Department of Obstetrics and Gynecology Southern Medical College Chittagong, Bangladesh.

${ }^{4}$ Department of Obstetrics and Gynecology Rangamati Medical College Rangamati, Bangladesh.

${ }^{5}$ Marie Stopes Clinic

Chittagong, Bangladesh.
${ }^{*}$ Correspondence to:

\section{Dr. Farida Yasmin} Assistant Professor

Department of Obstetrics and Gynecology Chittagong Medical College

Chittagong, Bangladesh.

Email:dr.shumi34cmc@gmail.com

Mobile : +8801773434095

www.banglajol.info/index.php/CMOSHMCJ

\begin{abstract}
Background: Ruptured uterus is an obstetric emergency, carrying increased risk of maternal and perinatal mortality and morbidity especially in the developing countries. To determine the various aspects such as antecedent factors, clinical profile, management, outcome of ruptured uterus in a tertiary hospital. Methods: This prospective cross-sectional study conducted in the Department of Obstetrics and Gynecology in Chittagong Medical College Hospital, Chittagong, from January 2010 to December 2010. 70 consecutive admitted patients during this period was taken in this study. Results: During study period total 13635 obstetric patients were admitted and among them 70 cases were of ruptured uterus which gives an incidence of $0.5 \%$. $92.85 \%$ of the women were multiparous. $77 \%$ patient did not have any antenatal care. $81 \%$ were illiterate and $82 \%$ belong to low socio-economic class. Common risk factors were mal-handling of labor by untrained dai (44\%) cephalopelvic disproportion (35\%) previous caesarean scar (34.28\%) shoulder presentation $15 \%$, abused of oxytocic drug (14\%). Shock and sepsis were the prominent presenting features. In most cases, the tear was in the lower segment and in 54 patients $(80 \%)$ the tear was complete. 25 (37\%) patients had sub-total hysterectomy, 22 had repair and $13(19.4 \%)$ had total hysterectomy. Maternal and fetal mortality rate was $11.42 \%$ and $88.5 \%$ respectively. Conclusion: A high incidence ( 1 in 195) of ruptured uterus mainly because of inadequate natal and intranatal care, high parity, mismanagement of labor, Low socio-economic condition and illiteracy.
\end{abstract}

Key words: Ruptured uterus; Intra-natal care; Intrapartem.

\section{INTRODUCTION}

Ruptured uterus is an obstetric emergency, carrying risk of maternal and perinatal mortality and morbidity ${ }^{1}$. In spite of recent advances in modem obstetric practice, it remains the most life-threatening complication of pregnancy and labor, especially in the developing countries ${ }^{2}$. Inadequate obstetric services coupled with reluctance of the illiterate to accept even the limited services available have made ruptured uterus an ever-present obstetric problem in third world countries ${ }^{1}$.

It is reported that the uterine rupture occurs is $0.05 \%$ in all pregnancy ${ }^{2}$. Rates are lower in the western world mainly because of good antenatal care and advances in the management of labor ${ }^{3}$. The etiology of uterine rupture has been affected by the changing trends of obstetric practice. Today, the most common cause of ruptured uterus is silent rupture of a previous caesarean scar. Other predisposing factors for uterine rupture include obstructed labor, in appropriate induction or augmentation of labor with oxytocic agents, grand multiparity, uterine anomaly, fetal anomaly, previous uterine trauma, abnormal placentation ${ }^{4}$. 
A WHO systematic review of maternal mortality and morbidity in 2005 showed large differences in the incidence of uterine rupture among countries, in high-income countries the incidence of uterine rupture was approximately $1 \%$ women with a history of cesarean delivery and less than 1 per 10000 in women with an unscarred uterus in low-income countries, however, uterine rupture was found to be a far more common problem, with overall rates ranging between $01 \%$ and $1 \%$ of all births $^{5}$. In studies from Nigeria, Ghana, Ethiopia, and Bangladesh, about $75 \%$ of cases of uterine rupture occurred inwomen with an unscarred uterus, with obstructed labor being the most common cause. Case fatality rates ranged between $1 \%$ and $13 \%$ and perinatal mortality between $74 \%$ and $92 \%{ }^{6,7}$.

This obstetric hazard is also associated with maternal morbidities such as vesicovaginal fistula, rectovaginal fistula, bladder rupture, foot drop, psychological trauma, anemia and in the long term because of the surgical intervention, the woman may be sterilized which can lead to divorce and loss of economic support ${ }^{8}$.

Uterine rupture accounts for significant number of maternal death in Bangladesh. The incidence of ruptured uterus in Dhaka Medical College Hospital (DMCH) is $0.85 \%$ of total admission ${ }^{1}$. In a study in Sir Salimullah Medical College and Mitford Hospital (SSMC\&MH) was 1 in 104.4 deliveries another study performed in SSMC between 1986- 1988 showed that there was one ruptured uterus per 102 hospital deliveries ${ }^{9,10}$. Ruptured uterus is a preventable obstetric complication. The high maternal morbidity, mortality and fetal mortality that follow uterine rupture calls for an integrated effort to prevent its causes. Good antenatal and intra-natal care, family planning services, prompt referral, availability of transportation and obstetric care are the essential factors to prevent uterine rupture and to decrease the maternal mortality, fetal mortality and maternal morbidity associated with it ${ }^{11}$.

\section{MATERIALS AND METHODS}

This prospective cross-sectional study conducted in the Department of Obstetrics and Gynecology in Chittagong Medical College Hospital, from January 2010 to December 2010. 70 patients were included in this study. All patients admitted with ruptured uterus were included whereas rests were excluded from the study. Informed consent was taken from each patient or legal guardian and the research protocol approved by the Ethical Committee. Data was collected through interviews and clinical evidences from the labor ward, operation theatre records and the patients' case files. The information collected comprise patient characteristics such as age, socioeconomic status, parity, weeks of gestation, number of previous cesarean sections, surgical findings, type of operation, whether antenatal care was taken or not and maternal and fetal mortality and morbidity. All data was analyzed and processed by computer and statistical analysis was done by using SPSS. Statistical analysis was done using Microsoft Excel. Frequency and percentage of each parameter was calculated and analyzed.

\section{Operational Definition}

Ruptured uterus: Total disruption of the wall of the pregnant uterus with or without extrusion of its contents. It is a grave obstetric complication. It may occur during labor, delivery and occasionally during the later weeks of pregnancy. Incidence is $0.05 \%$ for all pregnancies.

\section{RESULTS}

Table 1 : Socio-demographic characteristics.

$\begin{array}{lcc}\text { Variables } & \text { Frequency (n) } & \text { Percent (\%) } \\ \text { Age } & & \\ & 10 & 14.28 \\ 15-19 \text { years } & 36 & 51.42 \\ 20-29 \text { years } & 20 & 28.57 \\ 30-39 \text { years } & 04 & 5.70 \\ \quad 40 \text { and above } & & \\ \text { Residence } & 61 & 87.14 \\ \quad \text { Rural } & 09 & 12.86 \\ \quad \text { Urban } & & \\ \text { Economic status } & 00 & 00 \\ \text { Upper } & 12 & 17.14 \\ \text { Middle } & 58 & 82.85 \\ \text { Lower } & \end{array}$

The peak incidence was found between 20-29 years' age group. The youngest patient was 17 years and the oldest one 43 years of age. $61(87.14 \%)$ of the 70 cases came from rural areas and 9 $(12.9 \%)$ were from urban area. $58(82.85 \%)$ patients were from poor background, only $12(17.14 \%)$ were from middle class families.

Table 2 : Distribution of cases regarding Antenatal care.

\begin{tabular}{lcc} 
Antenatal care & No. of cases & Percent \\
$\begin{array}{l}\text { 1. Un booked } \\
\text { 2. Booked }\end{array}$ & 54 & 77.14 \\
$\quad$ - Regular & 2 & \\
$\quad$ - Irregular & 14 & 2.86 \\
\hline
\end{tabular}

$54(77.14 \%)$ of cases had no antenatal check-up at all. 14 $(20 \%)$ cases attended antenatal clinics irregularly. Only two patients attended antenatal clinic regularly.

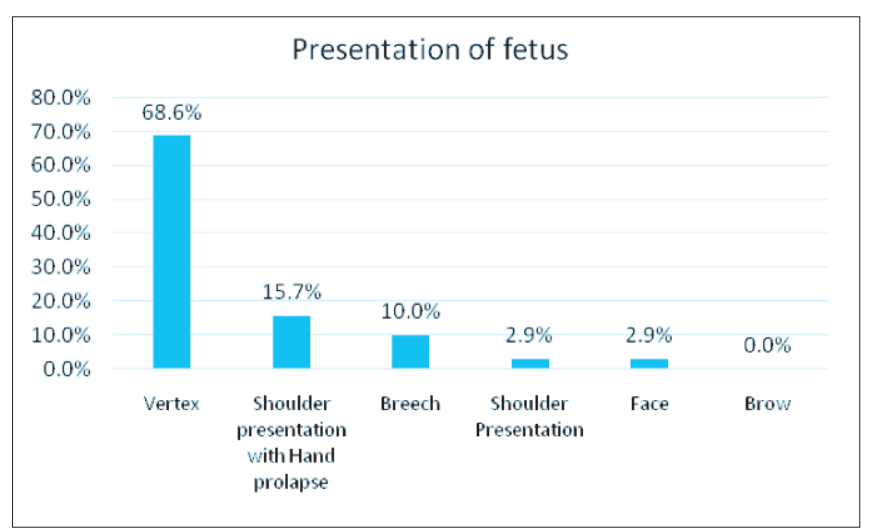

Figure 1 : Presentation of fetus $(n=70)$. 
Out of 70 cases. $48(68.57 \%)$ patients had vertex presentation and $11(15.73 \%)$ patients presented with hand prolapse.

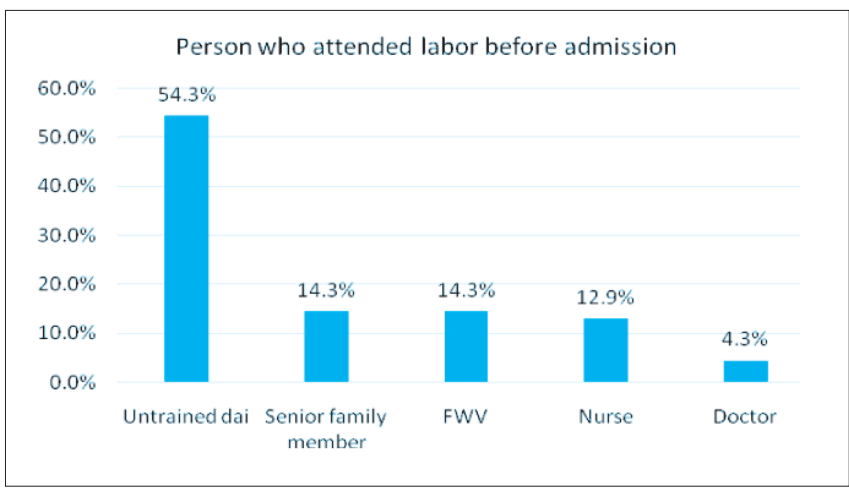

Figure 2 : Person who attended labor before admission $(n=70)$.

Most of the patients of rupture uterus 38 (54.28\%) cases were first handled by untrained dai at home and $10(14.28 \%)$ cases by family member, $10(14.28 \%)$ by FWV, 9 (12.80\%) by nurse and only $3(4.28 \%)$ by doctor.

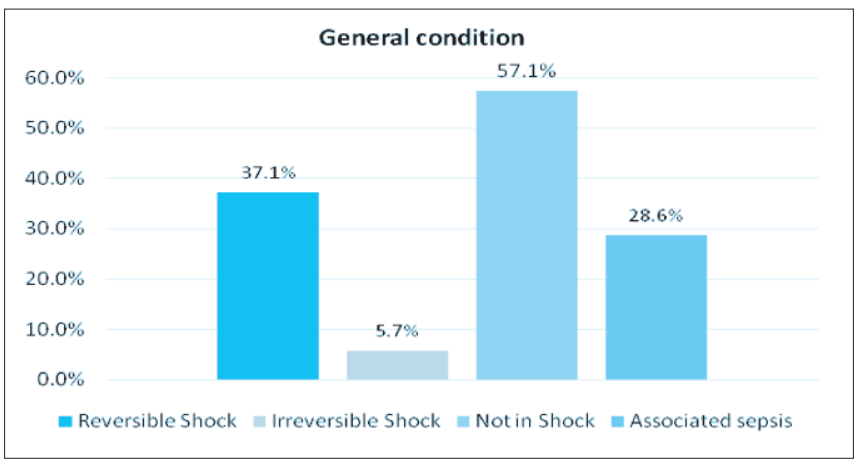

Figure 3 : General condition of the patient at the time of admission.

$26(37.14 \%)$ patients come with reversible shock, 4 (5.71\%) patients were in irreversible shock. There was associated sepsis in $20(28.57 \%)$ cases.

Table 3 : Laparotomy Findings.

\begin{tabular}{|c|c|c|}
\hline Per operative Findings & No. of patient $(n=67)$ & Percent \\
\hline \multicolumn{3}{|l|}{ Type of rupture } \\
\hline Complete & 54 & 80.60 \\
\hline Incomplete & 13 & 19.40 \\
\hline \multicolumn{3}{|l|}{ Site of Rupture } \\
\hline Anterior wall lower segment & 41 & 61.19 \\
\hline Antero lateral wall (L shaped) & 17 & 25.37 \\
\hline Posterior wall lower segment & 1 & 1.49 \\
\hline Upper segment only through fundus & 1 & 1.49 \\
\hline \multicolumn{3}{|l|}{$\begin{array}{l}\text { Lateral wall (upper and lower } \\
\text { segment with frequent extension to }\end{array}$} \\
\hline cervix and vagina) & 4 & 5.97 \\
\hline Extension to bladder & 3 & 4.48 \\
\hline
\end{tabular}

Complete rupture occurred in 54 cases and 13 cases had incomplete rupture.
Table 4 : Risk factor.

\begin{tabular}{llrr} 
Nature of rupture & Causes & No. of cases * & Percent \\
& Disproportion & & \\
& (due to contracted pelvis) & 25 & 35.71 \\
& Transverse lie with hand & & \\
& prolapse & 11 & 15.71 \\
& Hydrocephalus & 3 & 4.29 \\
1. Rupture in & Shoulder presentation & 2 & 2.86 \\
unscarred uterus & Breech & 7 & 10.00 \\
& Face & 2 & 2.86 \\
& Grandmultiparity & 11 & 15.71 \\
& manhandling by dai & 31 & 44.29 \\
& Craniotomy & 1 & 1.43 \\
2. Rupture of & Oxytocin induction & 10 & 14.29 \\
scarred uterus & Classical scar & 2 & 2.86 \\
& L S C S scar & 22 & 31.43 \\
\hline
\end{tabular}

Cephalopelvic disproportion (35.71\%) neglected transverse lie with hand prolapse $(15.71 \%)$ mal handling by untrained dai $(44.29 \%)$ were the main responsible factors. 24 cases of ruptured uterus associated with previous caesarean scar. Grand multiparity was also an important factor (15.71\%). Injudicious use of oxytocin outside the hospital causes ruptured uterus in $10(14.29 \%)$ cases.

* Many of patients were exposed to more than one risk factor.

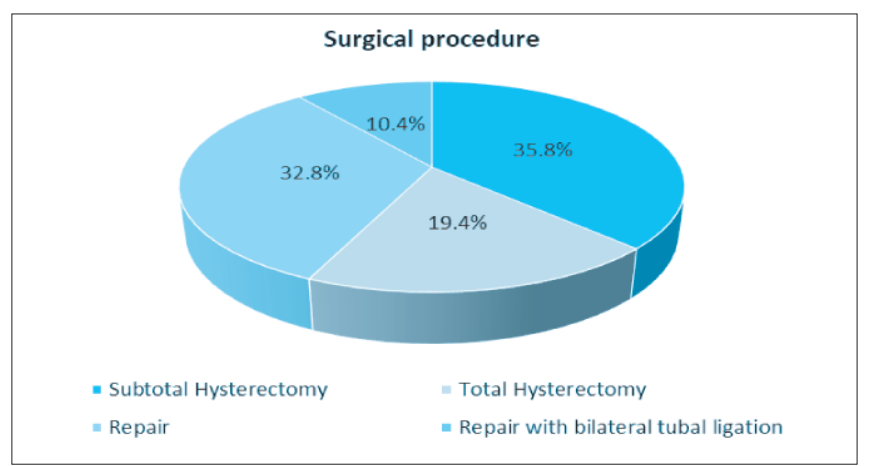

Figure 4 : Surgical procedure carried out $(n=67)$.

Subtotal Hysterectomy was performed in majority of cases $35.82 \%$. Total Hysterectomy was done in $19.40 \%$ cases. $32.84 \%$ patient underwent repair of rupture. In 3 cases no surgical intervention was possible before patient died.

Table 5 : Cause of maternal morbidities.

\begin{tabular}{lrc} 
Causes & No. of cases* $(\mathbf{n}=\mathbf{6 2})$ & Percent $(\%)$ \\
Fever $\left(100.4^{\circ}\right.$ F or more $)$ & 24 & 38.71 \\
Shock & 26 & 41.94 \\
Abdominal wound infection & 22 & 35.48 \\
Peritonitis & 17 & 27.42 \\
UTI & 9 & 14.52 \\
Wound infection requiring & & \\
2ndary suture & 10 & 16.13 \\
Burst abdomen & 4 & 6.45 \\
ARF & 3 & 4.84 \\
Malaria & 1 & 1.61 \\
Urinary fistula & 1 & 1.61 \\
\hline
\end{tabular}


Sepsis was the most common causes of post-operative morbidity. 24 of patients had post-operative pyrexia for 2 or 3 successive days. Wound infections (Mild to severe) was a feature in $22(35.48 \%)$ cases and 10 required secondary suture and $4(6.45 \%)$ developed complete wound disruption (Burst abdomen). Peritonitis with abdominal distension was a prominent feature in $17(27.41 \%)$ cases. 9 cases had UTI. 3 patient had ARP and survived surprisingly by adequate treatment. There were 3 bladder injury cases which were repaired and one patients developed urinary fistula later was recorded in this study.

* Many patients had more than, one complication.

" Alive asphyxiated - Fresh stillbirth = Macerated

Figure 5 : Fetal Outcome.

$8(11.42 \%)$ babies survived the disaster and it represent overall perinatal mortality of $88.57 \%$.

\section{DISCUSSION}

Rupture of uterus is a life-threatening complication of pregnancy and labor in developing country. Where the level of obstetric care is adequate at all levels, its occurrence is rare. Poverty, ignorance, illiteracy, traditional practices and high parity make this serious complication a common occurrence ${ }^{12}$.

In Chittagong Medical College Hospital, total number of ruptured uterus cases were 70 and total admitted obstetric cases were 13635, which gives an incidence of 1 in 195 deliveries. The highest incidence so far reported was I in 38 deliveries in Ethiopia while the lowest has been I in 16,849 in USA ${ }^{13,14}$. High incidence of ruptured uterus cases admitted in Chittagong Medical College Hospital was because of only referral hospital in this greater region.

Exact incidence is difficult to calculate in Bangladesh because of lack of countrywide statistical data.

The high incidence of ruptured uterus has been at to poor antenatal and ineffective intra natal care. In this study only 16 $(22.7 \%)$ patients had antenatal care i.e. $77.1 \%$ was lacking in antenatal care. Megafu in Nigeria observed that $96.2 \%$ of the cases of ruptured uterus and Rahman in Libya observed that $95 \%$ of his cases of ruptured uterus lacked prenatal care ${ }^{15}$.

Multiparty is generally recognized as an important risk factor in the etiology of ruptured uterus. This study showed that ruptured uterus occurs in grand multiparty (15.7\%). In Megafu's study from Nigeria $65.2 \%$ of the women were of parity two and above and similar findings have also been reported by others (Gohien, Ralunan) ${ }^{16}$.

There were five cases of ruptured uterus in primigravida which is unusual. Two cases were due to injudicious administration of oxytocin outside the hospital. Another three cases were due to manhandling by untrained dai in remote rural areas.

It was also observed from the present study that socioeconomic background had a vital role in the incidence of ruptured uterus. Most of the patients $58(83 \%)$ where from poor class and $12(17 \%)$ from middle class and none from rich family.

Previous caesarean section is the most important predisposing factor for the occurrence of uterine rupture. In this series 24 $(34.28 \%)$ cases were previous history of caesarean section.

Cephalopelvic disproportion (35\%) and transverse lie with hand prolapse $(15.7 \%)$ were the most frequent causes of ruptured uterus in present study, Chen in Singapore showed that ratio of the cases with scarred uterus against those with unscarred uterus was $3: 1^{17}$. The commonest antecedent factor was previous lower segment caesarean section. Most of the patients were exposed to more than one factor.

Shock and septicemia were a prominent feature in majority of cases Out of 70 patients 30 patients $(42.85 \%)$ were in shock and $20(28.6 \%)$ had septicemia.

The lower segment was the commonest site of the rupture in the present series, which is similar to that reported by Konje and also similar to findings in most other studies ${ }^{18}$. This may be explained by the fact that most of the rupture was those of lower segment scars, in this study, $54(80.5 \%)$ case was complete rupture and $13(19.4 \%)$ case was incomplete rupture. This is contrary to the study of Konje where incomplete rupture $(53.2 \%)$ was more common than complete rupture $(46.8 \%)^{18}$.

In present series, out of 67 patients $22(32.83 \%)$ patients had undergone repair, $7(17.10 \%)$ patients had undergone repair with bilateral tubectomy and $25(37.31 \%)$ patients had undergone sub-total hysterectomy and $13(19.4 \%)$ patients had undergone total hysterectomy. Hysterectomy was the treatment of choice in the present series. In a study by Fofie and Baffoe hysterectomy was performed $68.2 \%$ cases $(24.4 \%$ subtotal and $43.8 \%$ total) as against $23.3 \%$ uterine repair ${ }^{19}$.

In this study, 8 patients out of 70 cases of ruptured uterus, died giving a mortality rate of $11.42 \%$. In contrast to $9.8 \%$ reported by Fofie and Baffoe from Ghana.

In this series there was very high foetal mortality (88.5\%), only 9 foetuses survived from a scarred ruptured uterus. A Gessessew, Melese MM Ethopia showed that the perinatal mortality was $98.1 \%{ }^{20}$. 
Paralytic ileus and sepsis were the main post-operative complication in the present series. The other complications were acute renal failure, shock, fever, and urinary tract infection. Interference outside the hospital, malnutrition, anemia, dehydration and a low general condition of the patient at the time of admission were probably the responsible factors for the development of the sepsis.

\section{CONCLUSION}

Ruptured uterus is still a common obstetric tragedy in Bangladesh. Many patients came in hospital after long neglected labor. A high incidence (1 in 195) of ruptured uterus cases were mainly because of inadequate natal and intra natal care, high parity, mismanagement done by midwives. Low socio-economic condition, illiteracy and lack of knowledge of people are the contributory factors in causing the complications.
Thus, high maternal and fetal death rates can be reduced by providing health education, community based maternity care making EOC services available at all levels, establishment of first referral health centers with adequate facilities. Easy access to family planning service and also skillful training of health services providers will definitely help in changing the situation.

\section{DISCLOSURE}

All the authors declared no competing interest.

\section{REFERENCES}

1. EKPO, E.E. Uterine rupture as seen in the University of calabar Teaching Hospital, Nigeria: a five-year review. Journal of Obstetrics and Gynaecology. 2000;20(2): 154-156.

2. Lynch JC, Pardy JP. Uterine rupture and scar dehiscence. A five year survey. Anaesth Intensive Care. 1996;24:699-704.

3. Chuni N. Analysis of uterine rupture in a tertiary center in Eastern Nepal: Lessons for obstetric care. J Obstet Gynaecol Res. 2006;32:574579 .

4. Miller DA, Diaz FG, Paul RH. Vaginal birth after cesarean: A 10-year experience. Obstet Gynecol. 1994;84:255-256

5. Hofmeyr GJ, Say L, Gulmezoglu AM, WHO systematic revie of maternal mortality and morbidity: The prevalence of uterine rupture. BJOG. 2005; 12(9):1221-1228.

6. Hofmeyr GJ. Obstructed labor: Uusing getter technologies to reduce mortality.lnU Gynecol Obstet. 2004;85 (Suppl 1):562-572.

7. Khanam RA, Khatun M. Ruptured uterus an ongoing tragedy of motherhood. Bangladesh Med Res Counc Bull. 2001;27 (2):43-47.

8. Philpott RH. Obstructed labour. Clinics in obstetrics and gynecology. 1982;9(3):625-640.

9. Begum A. Ruptured Uterus-A Study of 32 Cases. Bangladesh J Obstet Gynaecol. 1997; 12 (1):29-35.

10. M.Nessa A Ruptured uterus: A study of 46 cases Obstetrics and Gynaecological case records and commentaries for MRCOG examination. 1990;276.

11. Amanael Gessessew. Mengiste M Melese . Ruptured uterus-eight year retrospective analysis of causes and management outcome in Adigrat Hospital, Tigray Region, Ethiopia. Ethiop.J.Health Dev. 2002; 1 6(3):241-245.

12. Begum A. Ruptured uterus- Astudy of 32 cases. J Bangladesh College Physicians and Surgeons. 1994; 12(1): 29-35.

13. Chamiso B. Rupture of pregnant uterus in Shashemene General Hospital South Shoa Ethiopia (A three year study of 57-cases). EthiopMed-j. 1995;33(4):251.

14. Miller DA Interpartum rupture of the unscarred uterus obs \& Gynae. 1997; 89:671.

15. Oxumbala BC. Emergency obstetric hysterectomy in Eastern Nigeria. Int. Surgl. 991;76(2):109.

16. D Golen. Early spontaneous rupture of the post-myomectomy gravid uterus. Int J gynaecol obstet. 1990;31:167.

17. Chen LH. A ten year review of uterine of uterine rupture in modern obstetric practice. Ann- A cod-Med-Singapore. 1995;24(6):830.

18. JC Konje. Ruptured uterus in Ibadan. A twelve year review. Int J gynaecol and obstet. 1990:32:207-211.

19. Fofie C. O. and Baffoe P. A two years review of Uterine rupture in A Regional Hospital, Wa, Upper west region, Ghana. 2010; 44 (3): 98-102.

20. Gessessew A, Melese M M. Ruptured uterus: Eight years retrospective analysis causes and management outcome in a adigrat Hospital, Tigray Region, Ethiopa. Ethiop J Health Dev. 2002; 16(3):241-245. 